\title{
Eurolntervention
}

\section{Influence of age on the clinical outcomes of coronary revascularisation for the treatment of patients with multivessel de novo coronary artery lesions: sirolimus-eluting stent vs. coronary artery bypass surgery and bare metal stent, insight from the multicentre randomised Arterial Revascularisation Therapy Study Part I (ARTS-I) and Part II (ARTS-II)}

\author{
Victor M. Legrand ${ }^{1}$, MD; Scot Garg², MD; Patrick W. Serruys ${ }^{2 *}$, MD; Kari S. Virtanen ${ }^{3}$, MD;
} Günter Szurawitzki ${ }^{4}$, MD; Vassilis Voudris ${ }^{5}$, MD; Alessandro Fontanelli6, MD; Knut Endersen ${ }^{7}$, MD; $^{2}$ Igor Kranjec ${ }^{8}$, MD; Tessa Rademaker ${ }^{9}$, MSc; Christodoulos I. Stefanidis ${ }^{10}$, MD; Kristel Wittebols ${ }^{11}$, MSc

1. CHU Sart Tilman, Liège, Belgium; 2. Thoraxcenter, Erasmus Medical Center, Rotterdam, The Netherlands; 3. Helsinki University Central Hospital, Helsinki, Finland; 4. Elisabeth Krankenhaus, Essen, Germany; 5. Onassis Cardiac Surgery Center, Athens, Greece; 6. San Bortolo Hospital, Vincenza, Italy; 7. Riskhospital, Oslo, Norway; 8. Clinical Centre Ljubljana, Ljubljana, Slovenia; 9. Cardialysis BV, Rotterdam, The Netherlands; 10. Hippokratio Hospital, Athens, Greece; 11. Cordis, a Johnson \& Johnson Company, Waterloo, Belgium

The authors have no conflict of interest to declare.

\section{KEYWORDS}

Ageing, coronary artery disease,

revascularisation, bare metal stents, sirolimus-eluting stents, surgery

\begin{abstract}
Aims: We sought to evaluate the prognostic impact of age on the procedural results and subsequent clinical outcomes in patients with multivessel disease (MVD) treated either by coronary artery bypass surgery (CABG) or by percutaneous coronary intervention $(\mathrm{PCl})$ with or without drug eluting stents, based on data of the Arterial Revascularisation Therapies Study (ARTS) part I and part II. The potential influence of age in determining the most appropriate revascularisation strategy for patients with MVD is largely unknown.

Methods and results: Three year clinical outcome of ARTS I patients randomised to PCI with bare metal stent (BMS) $(n=600)$ or CABG $(n=605)$, and matched patients treated by PCl with sirolimus-eluting stents (SES) in ARTS II ( $n=607)$ were reviewed according to four age quartiles. Endpoints were measured in terms of major adverse cardiac and cerebrovascular events MACCE) during hospital stay and up to three years. The frequency of female, diabetes, hypertension, peripheral vascular disease, pulmonary disease, as well as lesion complexity increased with age. At three years, MACCE free survival was comparable between patients treated by CABG or SES PCI, regardless of age quartile. The incidence of MACCE was higher among ARTS I BMS treated patients in all but the second age quartile. This was primarily related to a higher need for repeat revascularisation among BMS treated patients. However, age, which emerged as a strong independent predictor of MACCE following CABG $(p<0.005)$, was not predictive of adverse events following PCl. Conversely, diabetes was the strongest independent predictor of MACCE among PCl treated patients ( $p<0.02$ ), but didn't affect three-year outcomes following CABG. Conclusions: Age seems to influence the CABG outcome in-hospital but not PCI. PCI-SES could offer lower immediate risk in patients with MVD and comparable long-term outcome as CABG especially in older patients. The worst outcome of PCI-BMS group is primarily related to the need for repeat revascularisation. Diabetes is the most important predictor of MACCE following PCI.
\end{abstract}

* Corresponding author: Thoraxcenter, Ba 583, Dr. Molewaterplein 40, 3015 GD, Rotterdam, The Netherlands

E-mail: p.w.j.c.serruys@erasmusmc.nl 


\section{Introduction}

Coronary artery disease (CAD) is the leading cause of mortality worldwide. The prevalence of CAD increases with age, and this coupled with increasing life expectancy has led to a sharp rise in the number of elderly patients undergoing percutaneous coronary intervention $(\mathrm{PCl})$ and coronary artery bypass grafting surgery (CABG). ${ }^{1}$ In comparison to their younger counterparts, older patients with $C A D$ usually present with more diffuse atherosclerosis and a higher plaque burden. ${ }^{2}$ In addition non-cardiac comorbidities such as renal insufficiency and impaired pulmonary function are also more prevalent with increasing age. This high risk profile of elderly $C A D$ patients contributes to their increased complication rates, both after $\mathrm{PCl}^{3}$ and $\mathrm{CABG} .{ }^{4}$ Consequently, numerous clinical studies have confirmed that a correlation exists between clinical outcomes from either method of revascularisation, and the patient's age. ${ }^{5-9}$ On the other hand elderly patients have been shown to derive more benefit from invasive coronary revascularisation than from optimal medical therapy, ${ }^{9-11}$ and one study ${ }^{9}$ even concluded that elderly patients have a greater absolute risk reduction associated with revascularisation in comparison with younger patients. The most appropriate revascularisation procedure for older or younger patients remains controversial, primarily through the lack of clinical studies investigating a direct comparison of both treatment strategies.

The objective of the current investigation was to examine the prognostic impact of age on the procedural results, and subsequent early and late clinical outcomes in a contemporary cohort of patients with MVD treated by either CABG or PCI with or without drug eluting stents (DES).

\section{Methods}

\section{Study population and protocol}

The present study is a retrospective analysis of the ARTS I and II trials; the detailed protocols of both have been previously reported. . $^{12,13}$

Briefly, the study population includes the 1,205 patients from the ARTS-I study who were randomised to either bare metal stent (BMS) implantation $(n=600)$ or CABG $(n=605)$, and the 607 patients from the ARTS-II registry who were treated by sirolimuseluting stent (SES) implantation. In order to obtain a population comparable to ARTS-I, patients in ARTS-II were stratified per clinical site in order to ensure that at least one third of the included patients had triple vessel disease. All inclusion and exclusion criteria were the same for both trials, including the upper age limit, which was 80 years old. Patients were enrolled irrespective of whether they had stable or unstable angina or silent ischaemia. They were required to have MVD and at least one other significant lesion (>50\% diameter stenosis) in a different major epicardial artery suitable for stent implantation. Specific exclusion criteria included: patients with any prior coronary intervention, left main stem coronary disease, left ventricular ejection fraction of less than $30 \%$, overt heart failure, history of a cerebrovascular accident, transmural myocardial infarction in the preceding week, severe hepatic or renal disease and the need for concomitant major surgery. All patients gave written informed consent.
The pooled population of ARTS-I and ARTS-II was divided into four equal quartiles of 453 subjects based on age at trial inclusion. The first, second, third and fourth quartiles (mean \pm SD) consisted of patients $<54$ years ( $48.8 \pm 4.8$ years), $54-62$ years ( $58.5 \pm 2.1$ years), 62-68 years (65.6 \pm 1.9 years), and $68-83$ years old (73.3 \pm 3.1 years) respectively. Five patients ( 3 in ARTS I and 2 in ARTS II) older than 80 years were included.

\section{Data analysis and endpoints}

Clinical outcomes in each subgroup were compared according to the assigned treatment, (CABG, $\mathrm{PCl}$ with $\mathrm{BMS}$ or $\mathrm{PCI}$ with $\mathrm{SES}$ ) and analysis was performed on the outcome of each revascularisation procedure according to age quartiles. The primary endpoint was defined as the absence of any of the following major adverse cardiac and cerebral events (MACCE) within three years of inclusion in the trial: death (all-cause mortality), cerebrovascular accident, non-fatal myocardial infarction (MI), or any repeat revascularisation (either $\mathrm{PCl}$ or $\mathrm{CABG}$ ). ${ }^{12,14,15} \mathrm{MACCE}$ rate during hospital stay and at three years is assessed according to hierarchical classification. In hierarchical classification, only the worst event was counted as an event. Single adverse events are reported in a non-hierarchical way. Events for the present report were counted from the time of procedure for all the three arms. Complete three-year follow-up was available for all of the 1,812 study patients.

\section{Statistical analysis}

Statistical analysis was performed with SAS 6.12 software (SAS Institute Inc., Chicago, IL, USA). Continuous variables are expressed as mean \pm standard deviation (SD) and compared with use of Student's unpaired $t$-test. Categorical variables were reported as counts and percentages and compared using the Fisher's exact test for pair wise variables or the Chi-square for trend to examine the impact of age. Longitudinal event rates were evaluated using Kaplan-Meier estimates and compared with the log-rank test. To examine the impact of age in each treatment strategy, Cox Proportional Hazard models in SAS V8.2 was used. Both the age and the treatment subgroups were tested for interaction with predictor variables. This analysis was restricted to the MACCE. For the interaction tests between predictor variables and age group or treatment group, a likelihood ratio test was used by subtracting the summed $-2 \log (\mathrm{L})$ of the "by group" analysis from the $-2 \log (\mathrm{L})$ of the stratified (by age and by treatment) analysis, and comparing the outcome with a Chi-square distribution with the correct number of degrees of freedom. In case of a p-value $<0.05$ for the interaction, the "by group" analysis regression parameters were used.

\section{Results}

\section{Baseline characteristics}

Three patients died while waiting for surgery, and were subsequently excluded from the clinical outcome evaluation. Six patients initially assigned to BMS implantation were instead treated by surgery, and 19 patients initially assigned to surgery were instead treated with BMS. One patient assigned to stenting, and four patients assigned to surgery received only medical treatment. All patients assigned to SES implantation were treated according to protocol. 
The patient population between both trials was not matched, and consequently the mean age of patients in the ARTS-II trial which was $63 \pm 10$ years is slightly higher than that of the patients in the ARTS-I trial, whose mean ages were $61 \pm 9$ years and $61 \pm 10$ years for CABG and PCl, respectively. The patients included in the ARTSII registry had more complex lesions and anatomy as has been previously reported. ${ }^{16}$

Table 1 shows the baseline demographic and clinical characteristics of the enrolled patients. Increasing age is associated with an increased prevalence of diabetes mellitus, hypertension, peripheral artery disease, previous carotid artery surgery or cerebrovascular events, and chronic obstructive pulmonary disease. Conversely, the incidence of hypercholesterolaemia, obesity, family history of $\mathrm{Ml}$ or sudden death, previous $\mathrm{MI}$ and current smoking, as well as the percentage of males in the population were found to decrease with advanced age. In all quartiles, the majority of patients presented with stable angina.

Procedural characteristics are depicted in Table 2. As patients included in ARTS had to be amenable for PCl or CABG, it is not surprising that the number of lesions treated was not influenced by age and was similar in patients assigned to CABG or stent implantation. The left anterior descending artery was equally

Table 1. Demographics and patient characteristics ( $N=1,812$ patients).

\begin{tabular}{|c|c|c|c|c|c|}
\hline & $\begin{array}{c}Q 1 \\
30-54 y \\
N=453 \\
\end{array}$ & $\begin{array}{c}Q 2 \\
54-62 y \\
N=453 \\
\end{array}$ & $\begin{array}{c}Q 3 \\
62-68 y \\
N=453 \\
\end{array}$ & $\begin{array}{c}04 \\
68-83 y \\
N=453 \\
\end{array}$ & $\begin{array}{l}p \text {-value } \\
\text { (trend) }\end{array}$ \\
\hline Men & $87.2 \%$ & $81.7 \%$ & $73.1 \%$ & $64.2 \%$ & $<0.001$ \\
\hline Age $(m e a n \pm s d)$ & $48.8 \pm 4.8$ & $58.5 \pm 2.1$ & $65.6 \pm 1.9$ & $73.3 \pm 3.1$ & $<0.001$ \\
\hline BMI (mean \pm sd) & $27.7 \pm 3.9$ & $27.6 \pm 3.7$ & $27.3 \pm 3.6$ & $26.8 \pm 4.0$ & $<0.001$ \\
\hline Current smoking & $44.4 \%$ & $25.2 \%$ & $17.9 \%$ & $9.8 \%$ & $<0.001$ \\
\hline Diabetes mellitus & $14.8 \%$ & $19.6 \%$ & $22.5 \%$ & $24.1 \%$ & $<0.001$ \\
\hline Hypertension & $40.6 \%$ & $51.2 \%$ & $56.7 \%$ & $60.7 \%$ & $<0.001$ \\
\hline Hypercholesterolaemia & $66.7 \%$ & $63.7 \%$ & $64.1 \%$ & $58.3 \%$ & 0.014 \\
\hline Family history & $50.6 \%$ & $42.2 \%$ & $35.7 \%$ & $27.5 \%$ & $<0.001$ \\
\hline PVD & $3.1 \%$ & $4.4 \%$ & $7.3 \%$ & $8.6 \%$ & $<0.001$ \\
\hline CVA & & & & $1.8 \%$ & 0.034 \\
\hline Previous MI & $49.0 \%$ & $40.2 \%$ & $35.8 \%$ & $36.0 \%$ & $<0.001$ \\
\hline evious CABG & $0.0 \%$ & $0.0 \%$ & $0.0 \%$ & $0.0 \%$ & $\mathrm{~N} / \mathrm{A}$ \\
\hline Previous PCI & $0.9 \%$ & $1.3 \%$ & $2.0 \%$ & $1.5 \%$ & 0.29 \\
\hline arotid surgery & $0.0 \%$ & $0.7 \%$ & $1.1 \%$ & $.0 \%$ & 0.002 \\
\hline COPD & $1.5 \%$ & $3.8 \%$ & $6.9 \%$ & $5.7 \%$ & $<0.001$ \\
\hline Silent ischaemia & $7.3 \%$ & $7.1 \%$ & $7.3 \%$ & $6.6 \%$ & 0.74 \\
\hline Stable angina & $54.3 \%$ & $57.6 \%$ & $57.0 \%$ & $54.5 \%$ & 1.00 \\
\hline Unstable angina & $38.4 \%$ & $35.3 \%$ & $35.8 \%$ & $38.9 \%$ & 0.86 \\
\hline 1 vessel disease & $2.9 \%$ & $2.7 \%$ & $1.8 \%$ & $3.2 \%$ & 0.97 \\
\hline 2 vessel disease & $63.5 \%$ & $60.7 \%$ & $58.2 \%$ & $58.1 \%$ & 0.08 \\
\hline 3 vessel disease & $33.6 \%$ & $36.6 \%$ & $40.0 \%$ & $38.7 \%$ & 0.07 \\
\hline LVEF $(\%)($ mean \pm sd) & $59.2 \pm 12.1$ & $61.1 \pm 12.3$ & $61.6 \pm 12.3$ & $60.1 \pm 12.7$ & 0.21 \\
\hline Lipid lowering agent & $54.0 \%$ & $54.3 \%$ & $53.8 \%$ & $52.8 \%$ & 0.69 \\
\hline Beta blockers & $67.8 \%$ & $66.8 \%$ & $59.0 \%$ & $63.5 \%$ & 0.04 \\
\hline ACE inhibitors & $27.8 \%$ & 26.3 & $33.9 \%$ & 34.5 & 0.004 \\
\hline
\end{tabular}

BMI: body mass index; PVD: peripheral vascular disease;

CVA: cerebrovascular accident; MI: myocardial infarction; CABG: coronary artery bypass surgery; PCI: percutaneous coronary intervention; COPD: chronic obstructive pulmonary disease; LVEF: left ventricular ejection fraction; ACE: angiotensin converting enzyme
Table 2. Angiographic and procedural characteristics ( $N=1,778$ patients, $\mathrm{N}=5,404$ lesions).

\begin{tabular}{|c|c|c|c|c|c|}
\hline & $\begin{array}{c}Q 1 \\
30-54 y \\
N=453 \\
\end{array}$ & $\begin{array}{c}Q 2 \\
54-62 y \\
N=453 \\
\end{array}$ & $\begin{array}{c}Q 3 \\
62-68 y \\
N=453 \\
\end{array}$ & $\begin{array}{c}04 \\
68-83 y \\
N=453\end{array}$ & $\begin{array}{l}p \text {-value } \\
\text { (trend) }\end{array}$ \\
\hline $\begin{array}{l}\text { No. of treated lesions } \\
\text { (mean } \pm \text { sd) }\end{array}$ & $2.8 \pm 1.1$ & $2.8 \pm 1.0$ & $2.9 \pm 1.0$ & $2.9 \pm 1.1$ & 0.30 \\
\hline \multicolumn{6}{|l|}{ Location of lesions: } \\
\hline RCA & $32.9 \%$ & $29.4 \%$ & $28.6 \%$ & $28.5 \%$ & 0.013 \\
\hline LM & $0.0 \%$ & $0.1 \%$ & $0.0 \%$ & $0.1 \%$ & 0.54 \\
\hline LAD & $40.0 \%$ & $40.9 \%$ & $41.6 \%$ & $40.7 \%$ & 0.65 \\
\hline $\mathrm{LCX}$ & $27.1 \%$ & $29.7 \%$ & $29.9 \%$ & $30.8 \%$ & 0.047 \\
\hline \multicolumn{6}{|l|}{ Lesion length } \\
\hline Discrete $<10$ mm & $65.0 \%$ & $64.2 \%$ & $65.1 \%$ & $63.6 \%$ & 0.58 \\
\hline Tubular 10-20 mm & $26.6 \%$ & $26.5 \%$ & $26.9 \%$ & $26.7 \%$ & 0.90 \\
\hline Diffuse $>20 \mathrm{~mm}$ & $8.4 \%$ & $9.3 \%$ & $8.0 \%$ & $9.7 \%$ & 0.46 \\
\hline Bifurcation or SB & $33.2 \%$ & $33.9 \%$ & $33.7 \%$ & $33.2 \%$ & 0.96 \\
\hline \multicolumn{6}{|l|}{ Lesion classification } \\
\hline Type A/B1 & $37.2 \%$ & $32.5 \%$ & $31.6 \%$ & $31.8 \%$ & 0.003 \\
\hline Type B2/C & $62.8 \%$ & $67.5 \%$ & $68.4 \%$ & $68.2 \%$ & 0.003 \\
\hline \multicolumn{6}{|l|}{ Randomised to } \\
\hline ARTS-I CABG & $33.3 \%$ & $35.1 \%$ & $33.3 \%$ & $31.8 \%$ & 0.52 \\
\hline ARTS-I BMS & $38.4 \%$ & $31.3 \%$ & $33.1 \%$ & $29.6 \%$ & 0.012 \\
\hline ARTS-II SES & $28.3 \%$ & $33.6 \%$ & $33.6 \%$ & $38.6 \%$ & 0.002 \\
\hline \multicolumn{6}{|l|}{ In-hospital stay } \\
\hline Post PCI (days \pm sd) & $3.5 \pm 2.8$ & $3.3 \pm 2.6$ & $4.0 \pm 4.2$ & $3.8 \pm 3.0$ & 0.037 \\
\hline Post CABG (days $\pm s d)$ & $8.6 \pm 3.9$ & $8.8 \pm 3.4$ & $10.2 \pm 5.2$ & $10.9 \pm 6.5$ & $<0.001$ \\
\hline
\end{tabular}

revascularised within each age subgroups and more complex lesions were noted in older patients.

Based on the clinical and demographic data the calculated logistic EuroSCORE for each subgroup was $1.27 \pm 0.58,1.33 \pm 0.58,2.07 \pm 1.10$ and $3.58 \pm 1.95$, respectively. Finally, the average hospital stay increased with age and was longer among patients treated surgically.

\section{In-hospital clinical outcome}

In-hospital death and MACCE for each assigned treatment are presented in Table 3 according to age quartile. There was an age related increase in mortality and MACCE in patients treated surgically. The in-hospital mortality observed in these patients was comparable to the predicted mortality estimated by the EuroSCORE. Conversely, age had no significant influence on the in-hospital outcomes of patients assigned to percutaneous treatment, either with BMS or DES. In the youngest quartile (Q1) of patients assigned to BMS there was an excess MACCE as compared to SES PCI, which was primarily due to the increased repeat revascularisations, and myocardial infarctions in the BMS subgroup $(p=0.016)$. However, we may speculate that this observation is related to improvements in ARTS-II PCl techniques and medical management. In the oldest quartile (Q4) patients treated by SES PCI had less MACCE as compared to surgically treated patients $(2.3 \%$ vs. $9.0 \%, p=0.011)$; which was predominantly driven by a reduction in mortality $(0.0 \%$ vs. $3.5 \%, p=0.018)$.

\section{Three-year clinical outcome}

Patient mortality increased with age and this trend was significant for patients assigned to CABG and SES PCI (Table 4). A trend noted only in those patients having $\mathrm{PCl}$ was the increasing incidence of 
Table 3. In-hospital events (hierarchical MACCE and non hierarchical events up to hospital discharge, per patient) counted since date of procedure.

\begin{tabular}{|c|c|c|c|c|c|}
\hline & $\begin{array}{c}Q 1 \\
30-54 y\end{array}$ & $\begin{array}{c}Q 2 \\
54-62 y\end{array}$ & $\begin{array}{c}Q 3 \\
62-68 y\end{array}$ & $\begin{array}{c}04 \\
68-83 y \\
\end{array}$ & $\begin{array}{l}p \text {-value } \\
\text { (trend) }\end{array}$ \\
\hline ARTS-I CABG & $N=150^{n}$ & $N=158^{n}$ & $N=150^{n}$ & $\mathrm{~N}=144$ & \\
\hline MACCE \% (n) & $2.0(3)$ & $5.1(8)$ & $7.3(11)$ & $9.0{ }^{\pi}(13)$ & 0.007 \\
\hline Death \% (n) & $0.0(0)$ & $0.6(1)$ & $1.3(2)$ & $3.5 *(5)$ & 0.009 \\
\hline CVA \% (n) & $0.0(0)$ & $2.5(4)$ & $0.0(0)$ & $1.4(2)$ & 0.68 \\
\hline MI \% (n) & $2.0(3)$ & $2.5(4)$ & $4.7(7)$ & $3.5(5)$ & 0.30 \\
\hline CABG \% (n) & $0.0(0)$ & $0.0(0)$ & $0.7(1)$ & $0.7(1)$ & 0.19 \\
\hline PCI \% (n) & $0.0(0)$ & $0.6(1)$ & $0.7(1)$ & $0.7(1)$ & 0.41 \\
\hline ARTS-I BMS & $\mathrm{N}=174$ & $\mathrm{~N}=142$ & $\mathrm{~N}=150$ & $\mathrm{~N}=134$ & \\
\hline MACCE \% (n) & $6.3 *(11)$ & $5.6(8)$ & $10.7^{\mathrm{q}}(16)$ & $5.2(7)$ & 0.78 \\
\hline Death \% (n) & $0.6(1)$ & $1.4(2)$ & $1.3(2)$ & $0.7(1)$ & 0.84 \\
\hline CVA \% (n) & $0.6(1)$ & $0.7(1)$ & $0.0(0)$ & $1.5(2)$ & 0.54 \\
\hline MI \% (n) & $3.4(6)$ & $2.8(4)$ & $4.0^{9}(6)$ & $0.7(1)$ & 0.28 \\
\hline CABG $\%(n)$ & $2.3(4)$ & $0.7(1)$ & $6.7 *(10)$ & $0.7(1)$ & 0.74 \\
\hline PCI \% (n) & $4.0(7)$ & $1.4(2)$ & $1.3(2)$ & $2.2(3)$ & 0.26 \\
\hline ARTS-II SES & $\mathrm{N}=128$ & $\mathrm{~N}=152$ & $\mathrm{~N}=152$ & $\mathrm{~N}=175$ & \\
\hline MACCE \% (n) & $0.8(1)$ & $2.0(3)$ & $3.3(5)$ & $2.3(4)$ & 0.31 \\
\hline Death \% (n) & $0.0(0)$ & $0.0(0)$ & $0.0(0)$ & $0.0(0)$ & $\mathrm{N} / \mathrm{A}$ \\
\hline CVA \% (n) & $0.0(0)$ & $0.0(0)$ & $0.0(0)$ & $0.0(0)$ & $\mathrm{N} / \mathrm{A}$ \\
\hline MI \% (n) & $0.0(0)$ & $1.3(2)$ & $0.0(0)$ & $1.1(2)$ & 0.49 \\
\hline CABG \% (n) & $0.0(0)$ & $0.7(1)$ & $1.3(2)$ & $1.7(3)$ & 0.11 \\
\hline PCI \% (n) & $0.8(1)$ & $0.7(1)$ & $2.0(3)$ & $0.0(0)$ & 0.60 \\
\hline
\end{tabular}

${ }^{*} p<0.02,{ }^{4} p<0.015$ vs. ARTS-II SES; ${ }^{n}$ one patient died before CABG and was not included; MACCE: major adverse cerebral and cardiovascular event; CVA: cerebrovascular accident; MI: myocardial infarction; CABG: coronary artery bypass graft; PCI: percutaneous coronary intervention

cerebrovascular accidents with increasing age. Not surprisingly, the need for repeat revascularisation was higher among $\mathrm{PCl}$ treated patients in all age quartiles when compared to surgery. However, the need for repeat PCI and CABG was dramatically reduced in ARTS-II SES treated patients by $60.8 \%, 26.9 \%, 59.6 \%$ and $45.4 \%$ in Q1, Q2, Q3 and Q4, respectively, as compared to ARTS-I BMS treated patients. The need for repeat revascularisation was not agedependent.

The 3-year event free survival in each treatment arm is depicted in Figure 1 according to age quartile. In brief, there was no significant difference in MACCE rate between patients allocated to CABG or SES PCI with similar outcomes noted for each age group. Conversely, the increased need for repeat revascularisation, specifically during the first year, resulted in a worse event free survival for ARTS-I BMS treated patients.

\section{Impact of age on event free survival}

A multi-variable analysis was conducted to determine the influence of age on outcome at three-years follow-up. Age together with hypertension and multiple long diffuse lesions were independent predictors of MACCE amongst surgically treated patients. In patients treated with SES PCI the presence of diabetes was the strongest independent predictor of MACCE, together with the absence of hypertension, a small number of lesions treated, and procedural duration (Table 5). Age was not found to be an independent predictor of three-year outcomes amongst patients treated by $\mathrm{PCl}$ either with SES or BMS.
Table 4. Clinical endpoints at three years (hierarchical MACCE and non hierarchical events up to 1,080 days, per patient) counted since date of procedure.

\begin{tabular}{|c|c|c|c|c|c|}
\hline & $\begin{array}{c}Q 1 \\
30-54 y\end{array}$ & $\begin{array}{c}Q 2 \\
54-62 y\end{array}$ & $\begin{array}{c}Q 3 \\
62-68 y\end{array}$ & $\begin{array}{c}04 \\
68-83 y\end{array}$ & $\begin{array}{l}p \text {-value } \\
\text { (trend) }\end{array}$ \\
\hline ARTS-I CABG & $\mathrm{N}=150^{\mathrm{n}}$ & $\mathrm{N}=158^{\mathrm{n}}$ & $\mathrm{N}=150^{\mathrm{n}}$ & $\mathrm{N}=144$ & \\
\hline MACCE \% (n) & $7.3(7)$ & $17.1(27)$ & $18.7(28)$ & $21.5(31)$ & 0.001 \\
\hline Death \% (n) & $1.3(1)$ & $3.2(5)$ & $4.7(7)$ & $8.3(12)$ & 0.003 \\
\hline CVA \% (n) & $0.0(0)$ & $5.1(8)$ & $4.0(6)$ & $3.5(5)$ & 0.15 \\
\hline MI \% (n) & $2.7(3)$ & $3.8(6)$ & $7.3(11)$ & $6.3(9)$ & 0.07 \\
\hline CABG $\%(n)$ & $0.7(1)$ & $1.3(2)$ & $1.3(2)$ & $1.4(2)$ & 0.57 \\
\hline PCI \% (n) & $4.0(2)$ & $8.2(13)$ & $4.7(7)$ & $6.9(10)$ & 0.56 \\
\hline ARTS-I BMS & $\mathrm{N}=174$ & $\mathrm{~N}=142$ & $\mathrm{~N}=150$ & $\mathrm{~N}=134$ & \\
\hline MACCE \% (n) & $32.2 *(56)$ & $28.9(41)$ & $40.0 *(60)$ & $35.1^{\S}(47)$ & 0.25 \\
\hline Death \% (n) & $2.9(5)$ & $3.5(5)$ & $4.7(7)$ & $5.2(7)$ & 0.25 \\
\hline CVA \% (n) & $1.7(3)$ & $0.7(1)$ & $2.7(4)$ & 9.0 (12) & $<0.001$ \\
\hline MI \% (n) & $8.6^{\S}(15)$ & $4.9(7)$ & $8.7(13)$ & $4.5(6)$ & 0.34 \\
\hline CABG $\%(n)$ & $9.2^{9}(16)$ & $7.0(10)$ & $12.7^{\#(19)}$ & $7.5^{\S}(10)$ & 0.94 \\
\hline PCI \% (n) & $20.7^{\S}(36)$ & $19.0(27)$ & $20.0 \pi(30)$ & $18.7(25)$ & 0.72 \\
\hline ARTS-II SES & $\mathrm{N}=128$ & $\mathrm{~N}=152$ & & $\mathrm{~N}=175$ & \\
\hline MACCE \% (n) & $13.3(17)$ & $20.4(31)$ & $17.8(27)$ & $24.0(42)$ & 0.042 \\
\hline Death \% (n) & $1.6(2)$ & $1.3(2)$ & $2.0(3)$ & $6.3(11)$ & 0.01 \\
\hline CVA \% (n) & $0.0(0)$ & $0.7(1)$ & $2.6(4)$ & $6.3(11)$ & 0.001 \\
\hline MI \% (n) & $0.8(1)$ & $4.6(7)$ & $3.3(5)$ & $4.0(7)$ & 0.63 \\
\hline CABG \% (n) & $2.3(3)$ & $2.6(4)$ & $3.3(5)$ & $2.3(4)$ & 0.4 \\
\hline PCI \% (n) & $10.9(14)$ & $16.4(25)$ & 9.9 (15) & $12.0(21)$ & 0.72 \\
\hline
\end{tabular}

* $P<0.001 ;{ }^{\text {IP }}<0.02 ;{ }^{\# P}<0.01 ;{ }^{\circledR} \mathrm{P}<0.05$ vs. ARTS-II SES; MACCE: major adverse cerebral and cardiovascular event; CVA: cerebrovascular accident; MI: myocardial infarction; CABG: coronary artery bypass graft;

PCI: percutaneous coronary intervention

Table 5. Predictors of MACCE.

\begin{tabular}{lllll} 
& \multicolumn{2}{c}{ CABG } & \multicolumn{2}{c}{ SES } \\
& $\boldsymbol{P}$ Hazard ratio & $\boldsymbol{P}$ & Hazard ratio \\
\hline Age group & 0.005 & 1.46 & 0.152 & 1.22 \\
Sex (female=0, male=1) & 0.398 & 0.78 & 0.303 & 1.41 \\
Diabetes & 0.324 & 1.37 & 0.018 & 1.90 \\
Hypertension & 0.047 & 1.73 & 0.042 & 0.57 \\
Hypercholesterolaemia & 0.585 & 0.86 & 0.785 & 1.09 \\
Family history & 0.519 & 0.84 & 0.841 & 0.95 \\
Previous vascular disease & 0.057 & 2.21 & 0.458 & 0.64 \\
Previous MI & 0.804 & 1.07 & 0.384 & 0.78 \\
Current smoker & 0.403 & 1.31 & 0.060 & 0.40 \\
Angina (stab/unstab/silent) & 0.089 & 0.67 & 0.764 & 0.94 \\
No. of diffuse lesions & & & & \\
(> 20 mm) & 0.001 & 2.35 & 0.394 & 0.83 \\
No. of calcified lesions & 0.216 & 0.78 & 0.621 & 1.06 \\
No. of lesions double guidewire & 0.451 & 0.86 & 0.470 & 1.11 \\
No. of lesions type B2/C & 0.246 & 0.82 & 0.069 & 1.32 \\
No. of lesions in LAD & 0.883 & 0.97 & 0.170 & 1.36 \\
Duration of procedure (min.) & 0.493 & 1.00 & 0.008 & 1.01 \\
No. of treated lesions & 0.680 & 1.06 & $<.0001$ & 0.53 \\
\hline
\end{tabular}

\section{Discussion}

The current investigation is the first to evaluate long-term outcomes of similar patients with MVD studied according to their age. Specifically, we assessed whether $\mathrm{PCl}$ with $\mathrm{BMS}, \mathrm{PCl}$ with $\mathrm{SES}$, or 

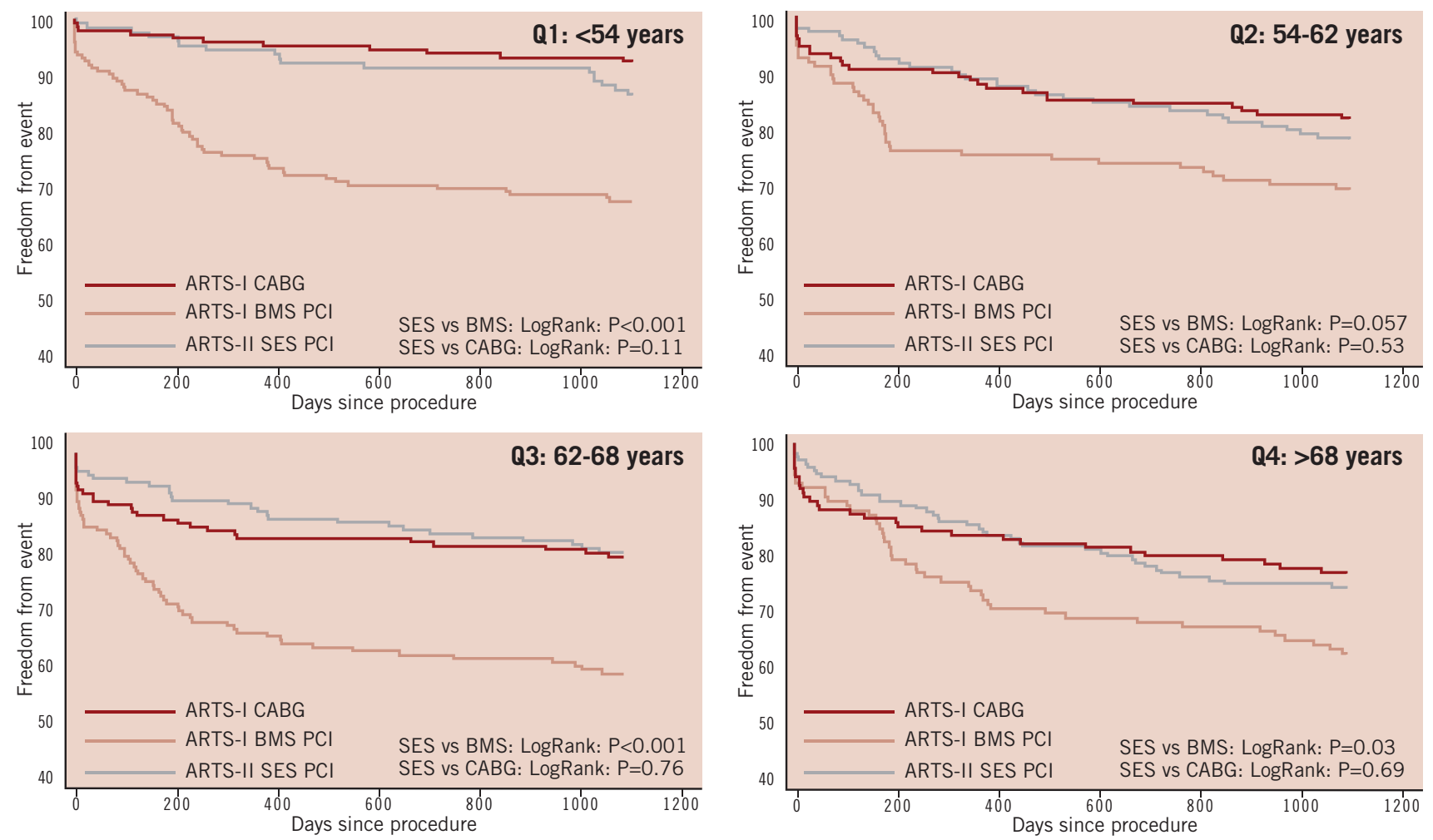

Figure 1. Kaplan-Meier curve to three years showing freedom from major adverse cardiac and cerebrovascular event (MACCE) according to age quartile in patients assigned to coronary artery bypass surgery (CABG), percutaneous coronary angioplasty with bare metal stent (BMS) and percutaneous coronary angioplasty with sirolimus-eluting stent (SES).

CABG is safer and/or more effective in particular age groups. In contrast to clinical registries, patients enrolled in the ARTS trials had less comorbidity, and a higher proportion of complete revascularisation.

At present the influence of age on long-term survival after $\mathrm{PCl}$ and CABG has not been adequately studied. Most of the data are derived from observational registries which doesn't allow for a direct comparison between $\mathrm{PCl}$ and $\mathrm{CABG}$, as elderly patients referred to one or the other revascularisation technique have different baseline characteristics. However a recent registry, which corrected for baseline differences, has shown a trend towards a better survival following surgery, despite the less invasive nature of $\mathrm{PCl}$, and the lower initial morbidity. ${ }^{17,18}$

There is a limited amount of data available from randomised trials on the influence of age on patient outcome after revascularisation. The BARI and SoS trial showed that survival was better with CABG compared with $\mathrm{PCl}$ irrespective of age. ${ }^{19,20}$ Conversely, a systematic review has shown that long term survival after $\mathrm{PCI}$ or $\mathrm{CABG}$ is similar among patients over the age of 65 when compared to those younger than $65 .^{21}$

Increasing age is associated with a lower three years survival among patients enrolled in CABG or SES arms of ARTS trials. However, neither $\mathrm{PCI}$ vs. $\mathrm{CABG}$ nor DES vs. BMS have a significant impact on survival up to three years, within each age quartiles.

This study has reiterated that important clinical and angiographic characteristics are age related. Older patients are more likely to be female, and when compared to their younger counterparts they are more likely to have comorbidities such as diabetes and hypertension. ${ }^{1-4}$ Furthermore, the elderly have more diffuse and complex coronary lesions on angiography. ${ }^{22,23}$ Therefore, in realworld clinical practice, when myocardial revascularisation is required, these important clinical characteristics are used on a case-by-case basis to make a clinical decision, without any wellestablished criteria for identifying those elderly patients more likely to benefit from $\mathrm{PCl}$ or CABG. Currently elderly patients with significant comorbidities tend to be treated by $\mathrm{PCl}$, not only because it is less invasive, but also based on the results from the AWESOME randomised trial which demonstrated similar survival outcomes in patients $>70$ years of age following either $\mathrm{PCl}$ or CABG. ${ }^{24}$

The data from the ARTS-I trial confirms a gradual increase of both mortality $(p=0.003)$ and morbidity $(p=0.001)$ with age amongst patients referred for CABG. Although the death rate also increased with increasing age among ARTS-II patients ( $p=0.01$ ), age (as assessed per quartile) was not an independent predictor of MACCE following $\mathrm{PCl}(p=0.15)$, whilst it did emerge as an important independent predictor of MACCE following surgery $(p=0.005)$. The selection of patients without severe comorbidities, with preserved left ventricular function and amenable to (near) complete revascularisation by $\mathrm{PCl}$ is the most likely explanation of the excellent results observed after stenting, particularly amongst those treated with SES. Those patients having surgery also had similar baseline characteristics, and were low surgical risk based on their 
calculated EuroSCORE. Therefore this study demonstrates that the impact of age on the outcomes after coronary revascularisation for MVD is significantly more important after surgery than after $\mathrm{PCl}$. Our data show that the risk from surgery is highest during the inhospital phase. Notably, the eldest patients (>68 years) undergoing surgery had a higher mortality rate than their counterparts treated by SES PCI. The in-hospital mortality observed in ARTS-I among surgically treated patients is in line with their predicted mortality based on the EuroSCORE. For patients included in the fourth quartile, the EuroSCORE predicted in-hospital mortality was of $3.58 \%$, which is almost identical to that actually observed in this study (3.5\%). For the younger age groups, the observed in-hospital mortality was slightly lower than that predicted by the EuroSCORE (0.0\% vs. $1.27 \%, 0.6 \%$ vs. $1.33 \%$ and $1.3 \%$ vs. $2.07 \%$ for Q1, Q2 and Q3). These results are in keeping with recent evidence which suggests that the logistic EuroSCORE over estimates mortality, and requires recalibration. ${ }^{25}$ The SYNTAX trial has also shown that early outcomes after $\mathrm{PCl}$ are related to initial lesion characteristics, however new evidence also suggests that these early outcomes after $\mathrm{PCl}$ can be influenced by adverse patient characteristics as assessed by the EuroSCORE. ${ }^{26,27}$

Clearly, the late outcomes after $\mathrm{PCl}$ are determined by the need for repeat revascularisation. At three-year follow-up, 173, 39 and 89 repeat revascularisations with $\mathrm{PCl}$ and/or surgery were performed in the ARTS-I PCl, ARTS-I CABG and ARTS-II PCl patients, respectively. Consistent with other trials of DES the use of SES lead to a dramatic improvement in the results of $\mathrm{PCl}$ in MVD as compared to $\mathrm{BMS} \mathrm{PCl}{ }^{28}$ This improvement has now been shown in our study to be independent of age. Despite the significantly lower repeat intervention rates with SES, CABG still remains associated with the lowest re-intervention rates in any age group quartile. Previous studies have shown that diabetes is a strong predictor of adverse outcome among patients treated by $\mathrm{PCl}$, most notably for those with MVD. ${ }^{29,30}$ Our results confirm that diabetes is the most important clinical risk factor for MACCE in patients treated by SES $\mathrm{PCI}$. In the surgical group diabetes was not associated with MACCE, which is in contrast to previous observational studies which have shown diabetes to be an independent predictor of mortality. ${ }^{31-33}$ The relative safety and efficacy of CABG decreases with increasing age, and this is independent of a patient's diabetic status. This data therefore suggests that young patients with diabetes benefit the most from surgery, and conversely, elderly patients without diabetes have a better outcome following SES PCI, compared to CABG. This implies that in diabetic patients with MVD, amenable to both $\mathrm{PCl}$ and $\mathrm{CABG}$, a patient's age should be considered when deciding the most appropriate method of revascularisation. In view of the paucity of evidence this subject needs to be accurately assessed in a specifically designed clinical trial in diabetic patients. Currently there are no published randomised studies of revascularisation specifically in diabetics; previous data have all been derived from post hoc subgroup analysis. Recently the early results of the CARDia trial, the first dedicated randomised trial of revascularisation in diabetics, showed no difference in outcome between diabetic patients with MVD treated with $\mathrm{PCl}$ or $\mathrm{CABG},{ }^{34}$ although no age distributions have yet been released. The full publication of CARDia is awaited, together with the results of the ongoing FREEDOM trial with the specific aim to clarify the role of CABG and PCI in diabetic patients with MVD. In the BARI 2D trial, Frye et $a^{35}$ reported that for many patients with both diabetes and coronary artery disease, optimal medical therapy rather than any intervention is an excellent first-line strategy, notably for those with less severe disease. When revascularisation by $\mathrm{PCl}$ is indicated, five year MACE free survival is not affected by the initial treatment strategy (medical or revascularisation). However, when revascularisation by $\mathrm{CABG}$ is deemed the more appropriate revascularisation strategy, MACE free survival is better in patients initially randomised to surgery. This trial also indicates that treatment strategy must be individualised for specific patients, based on the most appropriate evidence-based treatment recommendations.

\section{Study limitations}

Firm conclusions regarding the advisability of SES PCl in the oldest patients with multivessel disease cannot be drawn from the comparative evaluation of the ARTS-I and ARTS-II trials. Moreover, these data refer to selected patients with low co-morbidities, who were amenable to complete revascularisation with either $\mathrm{PCl}$ or CABG; importantly very old patients (octogenarians) were excluded from this study.

This study combines results of a randomised trial (ARTS I) and a registry (ARTS-II). Population of the registry was comparable (in term of inclusion criteria) but "not matched" besides a similar 2/3 $M V D$ ratio. We sought that age-corrected or propensity analysis would not be appropriate for the pooled ARTS-I and II population analysis. We therefore aimed to compare outcomes according to age quartile. However, using this approach, clinical and anatomical differences between patient's arms of each quartile are not fully compensated.

An important limitation to consider is the long time lag between the enrolment of patients in ARTS-I and ARTS-II, which may have influenced outcomes. The development of new surgical techniques and increasing use of arterial conduits may of lead to improved surgical outcomes if the CABG patients had been enrolled at the same time as ARTS-II SES patients. Conversely the patients in ARTS-II had a worse baseline and procedural risk profile compared to those included in ARTS-I, however better stent design, improved $\mathrm{PCl}$ technique and equipment, as well as the increased use of antiplatelet agents probably account for the improved procedural success in these patients.

\section{Clinical implications}

Increasing age has an adverse prognosis in MVD patients treated by CABG which is not observed following percutaneous revascularisation. The use of SES has improved the results of $\mathrm{PCl}$ such that they are now as good as those of surgery for any age quartile, furthermore this use of SES is not associated with an excess in post discharge death or $\mathrm{MI}$ as compared to BMS. At present multivessel $\mathrm{PCl}$ with SES in elderly patients is a valuable alternative to surgery, particular in the absence of diabetes. Whether SES PCI is equivalent to CABG, or even superior in elderly 
patients without diabetes, needs to be formally demonstrated in a head to head randomised trial, with long-term follow-up to help define the optimal treatment of these patients.

\section{Conclusions}

Age seems to influence the CABG outcome in-hospital but not PCl. $\mathrm{PCl}$-SES could offer lower immediate risk in patients with MVD and comparable long-term outcome as CABG especially in older patients. The worst outcome of $\mathrm{PCl}-\mathrm{BMS}$ group is primarily related to the need for repeat revascularisation. Diabetes is the most important predictor of MACCE following PCI.

\section{References}

1. Peterson ED, Alexander KP, Malenka DJ, Hannan EL, O'Conner GT, McCallister BD, Weintraub WS, Grover FL. Multicenter experience in revascularization of very elderly patients. Am Heart J 2004;148:486-92.

2. Weintraub WS. Coronary operations in octogenarians: can we select the patients? Ann Thorac Surg 1995;60:875-6.

3. Batchelor WB, Anstrom KJ, Muhlbaier LH, Grosswald R, Weintraub WS, O'Neill WW, Peterson ED. Contemporary outcome trends in the elderly undergoing percutaneous coronary interventions: results in 7,472 octogenarians. National Cardiovascular Network Collaboration. J Am Coll Cardiol 2000;36:723-30.

4. Alexander KP, Anstrom KJ, Muhlbaier LH, Grosswald RD, Smith PK, Jones RH,Peterson ED. Outcomes of cardiac surgery in patients $>$ or $=80$ years: results from the National Cardiovascular Network. J Am Coll Cardiol 2000;35:731-8.

5. Mullany CJ, Mock MB, Brooks MM, Kelsey SF, Keller NM, Sutton-Tyrrell K,Detre KM, Frye RL. Effect of age in the Bypass Angioplasty Revascularization Investigation (BARI) randomized trial. Ann Thorac Surg 1999;67:396-403.

6. Legrand VM, Serruys PW, Lindeboom WK, Vrolix MD, Fransen GM, Materne PH,Dekoster G, Seabra-Gomes R, Queiroz E Melo J. Influence of Age on the Outcomes of Percutaneous and Surgical Treatment of Multivessel Coronary Artery Disease Patients: Results from the Multicentre Randomized Arterial Revascularization Therapy Study. Geriatrics \& Aging 2002;5:9-16.

7. Garza JJ, Gantt DS, Van Cleave H, Riggs MW, Dehmer GJ. Hospital disposition and long-term follow-up of patients aged $>/=80$ years undergoing coronary artery revascularization. Am J Cardiol 2003;92:590-2.

8. Liistro F, Angioli P, Falsini G, Ducci K, Baldassarre S, Burali A, Bolognese L. Early invasive strategy in elderly patients with non-ST elevation acute coronary syndrome: comparison with younger patients regarding 30 day and long term outcome. Heart 2005;91:1284-8.

9. Graham MM, Ghali WA, Faris PD, Galbraith PD, Norris CM, Knudtson ML. Survival after coronary revascularization in the elderly. Circulation 2002;105:2378-84.

10. Trial of invasive versus medical therapy in elderly patients with chronic symptomatic coronary-artery disease (TIME): a randomised trial. Lancet 2001;358:951-7.

11. Pfisterer M, Buser P, Osswald S, Allemann U, Amann W, Angehrn W, Eeckhout E, Erne P, Estlinbaum W, Kuster G, Moccetti T, Naegeli B, Rickenbacher P. Outcome of elderly patients with chronic symptomatic coronary artery disease with an invasive vs optimized medical treatment strategy: one-year results of the randomized TIME trial. JAMA 2003;289:1117-23.
12. Serruys PW, Unger F, Sousa JE, Jatene A, Bonnier HJ, Schonberger JP,Buller $N$, Bonser $R$, van den Brand $M J$, van Herwerden LA, Morel MA, van Hout BA. Comparison of coronaryartery bypass surgery and stenting for the treatment of multivessel disease. N Engl J Med 2001;344:1117-24.

13. Serruys PW, Ong AT, Morice MC, De Bruyne B, Colombo A, Macaya C,Richardt G, Fajadet J, Hamm C, Dawkins K, O'Malley J, Bressers M, Dohonoe D on behalf of the ARTS II investigators. Arterial Revascularisation Therapies Study Part II - Sirolimus-eluting stents for the treatment of patients with Multivessel de novo coronary artery lesions. Eurolntervention 2005; 1:147-156.

14. Legrand VM, Serruys PW, Unger F, van Hout BA, Vrolix MC, Fransen GM,Nielsen T, Paulsen PK, Seabra Gomes R, de Queiroz e Melo JMG, Marques dos Santos Neves JP, Lindeboom W, Backx B. Three-year outcome after coronary stenting versus bypass surgery for the treatment of multivessel disease. Circulation 2004;109:1114-20.

15. Serruys PW, Ong AT, van Herwerden LA, Sousa JE, Jatene A, Bonnier JJ, Schönberger JPMA, Buller N, Bonser R, Disco C, Backx B, Hugenholtz PG, Firth BG, Unger F. Five-year outcomes after coronary stenting versus bypass surgery for the treatment of multivessel disease: the final analysis of the Arterial Revascularization Therapies Study (ARTS) randomized trial. J Am Coll Cardiol 2005;46:575-81.

16. Serruys PW, Daemen J, Morice MC, DeBruyne B, Colombo A, Macaya C, Richardt G, Fajadet J, Hamm C, Dawkins KD, Vranckx P, Bressers M, van Domburg R, Schuijer M, Wittebols K, Pieters M, Stoll HP. Three-year follow-up of the ARTS-II - sirolimus-eluting stents for the treatment of patients with multivessel coronary artery disease. Eurolntervention 2008;3:450-459.

17. Rodes-Cabau J, Deblois J, Bertrand OF, Mohammadi S, Courtis J, Larose E,Dagenais F, Déry JP, Mathieu P, Rousseau M, Barbeau G, Baillot R, Gleeton O, Perron J, Nguyen CM, Roy L, Doyle D De Larochellière R, Bogaty $P$, Voisine $P$. Nonrandomized comparison of coronary artery bypass surgery and percutaneous coronary intervention for the treatment of unprotected left main coronary artery disease in octogenarians. Circulation 2008;118:2374-81.

18. Kimura T, Morimoto T, Furukawa $\mathrm{Y}$, Nakagawa $\mathrm{Y}$, Shizuta $\mathrm{S}$, Ehara N,Taniguchi R, Doi T, Nishiyama K, Ozasa N, Saito N, Hoshino K, Mitsuoka H, Abe M, Toma M, Tamura T, Haruna Y, Imai Y, Teramukai S, Fukushima M, Kita T. Long-term outcomes of coronary-artery bypass graft surgery versus percutaneous coronary intervention for multivessel coronary artery disease in the bare-metal stent era. Circulation 2008;118(14 Suppl):S199-209.

19. Comparison of coronary bypass surgery with angioplasty in patients with multivessel disease. The Bypass Angioplasty Revascularization Investigation (BARI) Investigators. N Engl J Med 1996;335:217-25.

20. Zhang Z, Mahoney EM, Spertus JA, Booth J, Nugara F, Kolm P, Stables RH, Weintraub WS. The impact of age on outcomes after coronary artery bypass surgery versus stent-assisted percutaneous coronary intervention: one-year results from the Stent or Surgery (SoS) trial. Am Heart J 2006;152:1153-60.

21. Bravata DM, Gienger AL, McDonald KM, Sundaram V, Perez MV, Varghese R, Kapoor JR, Ardehali R, Owens DK, Hlatky MA. Systematic Review: The Comparative Effectiveness of Percutaneous Coronary Interventions and Coronary Artery Bypass Graft Surgery. Annals of Internal Medicine 2007;147:703-9.

22. Shirani J, Alaeddini J, Roberts WC. Comparison of modes of death and cardiac necropsy findings in fatal acute myocardial infarction in men and women $>75$ years of age. Am J Cardiol 2000;86:1010-2,A8,A10. 
23. Hirsch H, Lazar J, Marzo KP, Steingart RM. Percutaneous revascularization for unstable angina in the elderly. Coron Artery Dis 2000;11:315-22.

24. Ramanathan KB, Weiman DS, Sacks J, Morrison DA, Sedlis S, Sethi G, Henderson WG. Percutaneous intervention versus coronary bypass surgery for patients older than 70 years of age with high-risk unstable angina. Ann Thorac Surg 2005;80:1340-6.

25. Bhatti F, Grayson AD, Grotte G, Fabri BM, Au J, Jones M, Bridgewater $B$. The logistic EuroSCORE in cardiac surgery: how well does it predict operative risk? Heart 2006;92:1817-1820.

26. Romagnoli E, Burzotta F, Trani C, Siviglia M, Biondi-Zoccai GG, Niccoli G,Leone AM, Porto I, Mazzari MA, Mongiardo R, Rebuzzi AG, Schiavoni G, Crea F. EuroSCORE as predictor of in-hospital mortality after percutaneous coronary intervention. Heart 2009;95:43-8.

27. Serruys PW. The Synergy between Percutaneous Coronary Intervention with TAXUS and Cardiac Surgery: The SYNTAX Study. Primary Endpoint Results at One Year in the Randomized Cohort- TCT presentation, Washington. 2008.

28. Stettler C, Wandel S, Allemann S, Kastrati A, Morice MC, Schomig A, Pfisterer ME, Stone GW, Leon MB, de Lezo JS, Goy JJ, Park SJ, Sabaté M, Suttorp MJ, Kelbaek H, Spaulding C, Menichelli M, Vermeersch P, Dirksen MT, Cervinka P, Petronio AS, Nordmann AJ, Diem P, Meier B, Zwahlen M, Reichenbach S, Telle S, Windecker S, Jüni $P$. Outcomes associated with drug-eluting and bare-metal stents: a collaborative network meta-analysis. Lancet 2007;370:937-48.
29. The final 10-year follow-up results from the BARI randomized trial. J Am Coll Cardiol 2007;49:1600-6.

30. Daemen J, Kuck KH, Macaya C, LeGrand V, Vrolix M, Carrie D, Sheiban I, Suttorp MJ, Vrancks P, Rademaker T, Goedhart D, Schuijer M, Wittebols K, Macours N, Stoll HP, Serruys PWI. Multivessel coronary revascularization in patients with and without diabetes mellitus 3-year follow-up of the ARTS-II (Arterial Revascularization Therapies Study-Part II) trial. J Am Coll Cardiol 2008;52:1957-67.

31. Adler DS, Goldman L, O'Neil A, Cook EF, Mudge GH, Jr., Shemin RJ, DiSesa V, Cohn LH, Collins JJ. Long-term survival of more than 2,000 patients after coronary artery bypass grafting. Am J Cardiol 1986;58:195-202.

32. Thourani VH, Weintraub WS, Stein B, Gebhart SS, Craver JM, Jones EL, Guyton RA. Influence of diabetes mellitus on early and late outcome after coronary artery bypass grafting. Ann Thorac Surg 1999;67:1045-52.

33. Herlitz J, Wognsen GB, Emanuelsson H, Haglid M, Karlson BW, Karlsson T, Albertsson P, Westberg S. Mortality and morbidity in diabetic and nondiabetic patients during a 2-year period after coronary artery bypass grafting. Diabetes Care 1996;19:698-703.

34. Kapur A. Coronary Artery Revascularisation in Diabetes. The CARDia trial. Presentation at European Society of Cardiology meeting September $1^{\text {st }} 2008$.

35. The BARI 2D Study Group. A randomized trial of therapies for type 2 diabetes and coronary artery disease. N Engl J Med 2009;360: 2503-15. 